\title{
PUBLICATION ETHICS
}

\author{
IJOLTL Indonesian Journal of Language Teaching \& Linguistics \\ p ISSN: 2502 2326; e ISSN: 2502 8278 \\ Http://ijoltl.pusatbahasa.or.id
}

To hold publication core values and adherence to accepted publication ethics, IJOLTL employs the double -blinded peer review process for all articles. The purpose is to validate the integrity and novelty of the research work.

Authors must confirm the following that:

1. Submitted manuscripts must be the original work of the author(s);

2. Only unpublished manuscripts should be submitted;

3. It is unethical to submit a manuscript to more than one journal concurrently;

4. Any conflict of interest must be clearly stated;

5. The sources of data used in the development of the manuscript are acknowledged;

6. All errors discovered in the manuscript after submission must be swiftly communicated to the Editor.

Reviewers are expected to evaluate a manuscript for critical analysis, comparative analysis and most importantly for integrity and novelty of the research work.

Therefore, reviewers must confirm the following; that:

1. All manuscripts are reviewed in fairness based on the intellectual content of the article regardless of gender, race, ethnicity, religion, citizenry nor political values of author(s);

2. Any observed conflict of interest during the review process must be communicated to the Editor;

3. All information pertaining to the manuscript is kept confidential;

4. Any information that may be the reason for the rejection of publication of a manuscript must be communicated to the Editor.

Editors must confirm the following; that:

1. All manuscripts are evaluated in fairness based on the intellectual content of the paper regardless of gender, race, ethnicity, religion, citizenry nor political values of authors;

2. Information pertaining to manuscripts are kept confidential;

3. Any observed conflict of interest pertaining to manuscripts must be disclosed;

4. Editorial Board takes responsibility for making publication decisions for submitted manuscripts based on the reviewer's evaluation of the manuscript, policies of the journal editorial board and legal restrain acting against plagiarism, libel and copyright infringement. 


\title{
GUIDELINES TO AUTHORS
}

\author{
IJOLTL Indonesian Journal of Language Teaching \& Linguistics \\ p ISSN: 2502 2326; e ISSN: 2502 8278 \\ Http://ijoltl.pusatbahasa.or.id
}

1. IJOLTL welcomes submissions of articles on language, language teaching, literatures and linguistics for quarterly publication in the journal.

2. Submission of manuscript(s) should be by electronic submission with the text written in a single Microsoft Word file in the format of Times New Roman with font size as shown in the Template. All pages should be numbered consecutively starting from the title page.

3. Accompanying the article, author should submit a letter of introduction stating that the research article is original and has not been submitted or accepted for publication elsewhere. A cover letter of the article should include the corresponding author's full address and email or telephone/fax numbers.

4. The manuscript(s) should be double spaced, with a minimum of $2.5 \mathrm{~cm}$ margins on all sides. Manuscript structure is arranged as follows: Title, Affiliation, Abstract, Key words, Text, Acknowledgments, Literature cited, Appendix, Tables, and Figures. There is no restriction on the length of research papers and reviews, but authors are encouraged to be concise.

5. The subheading system of the articles should read as follows:

1. ALL CAPITALS, BOLD, LEFT JUSTIFICATION

1.1 Capitals Lowercase, Bold, Left Justification

1.1.1 Capital Lowercase, Italic $\sim$ Bold, Left Justification

6. The title of the manuscript should be brief (but informative enough to facilitate information retrieval), given preferably in single line; and a suggested running title should also be provided.

7. The name(s) of author(s) should be listed below the title and the corresponding author should be indicated with number in front of the name and his email address and phone number (if available).

8. The Affiliation(s) of all author(s) should be given clearly and briefly with their institutions, addresses with zip code and name of country.

9. Abstract should be brief, not more than 150 words, indicating the purpose/significance of the research, methodology, major findings and the most significant conclusion(s). The abstract should not contain literature citations that refer to the main list of references attached to the complete article. The abstract should be written as a single paragraph and should be in reported speech format (past tense); complete sentences, active verbs, and the third person should be used.

10. The authors must provide 3 8 key words for indexing purposes and to facilitate the retrieval of articles by search engines. Key words provided should be different from the words that make up the title of the article.

11. The text should be typed in single column, double space and justified. Should there be abbreviation(s) in the text, full term for which the abbreviation stands should precede its first use in the text. The text should be subdivided into the following sections: 
a. Introduction should be clear and concise, with relevant references to the nature of the problem under investigation as well as its background. There should be no sub headings. Excessive citations of literature (especially to support well known statements) and discussions marginally relevant to the paper; together with other information that adds length but little significance to the research, should be avoided. Only necessary and latest citations of literature that are required to indicate the reason for the research undertaken and the essential background should be given. References in the text are made as follows: (Myers, 2000) / (Myers, 2000; Edwards, 2010) / Barber, Odean and Zhu (2008) investigate...; the former being the name of the author, the latter edition year.

b. Methodology should be sufficiently detailed to enable scientist in that field of study to replicate them. A precise description of the selection of your observational or experimental subjects must be presented. The techniques and methodology adopted should be supported with standard references. Description of the methodology may be presented in sub heading including design, subject, instrument, data, and data analysis techniques or in a single concise paragraph.

c. Findings should be presented first, followed by a discussion of their significance presented in logical sequence. Data emerging from the study should be included, arranged in unified and coherent sequence(s). Only strictly relevant results should be presented; and figures, tables, and equations should be used for purposes of clarity and brevity. The same data should not be presented both in tabular and graphic forms. The discussion should state the implications of the findings and their limitations as well as the conclusion(s) drawn. It should relate the observations to previously published related studies and should be supported by relevant references. Long confused and irrelevant discussion should be avoided. Findings and Discussion may also be presented together.

d. Conclusions should not summarize information already present in the text or abstract. Recommendations, when appropriate, may be included.

12. Review article(s) should not contain methodology and/or results sections since there is neither any study to describe nor data to be analyzed. The format is as follows: Abstract, 3 8 key words, Introduction, Relevant section headings, Conclusion and References.

13. The Acknowledgement, if any should include the names of those who contributed substantially to the work described in the manuscript but do not fulfil the requirements for the authorship. It should also include name(s) of sponsor(s)/funding agency of the research.

14. The list of references should conform to the conventions specified in the Publication Manual of the American Psychological Association (APA) style under the heading of References. When referencing website, please include the full title and accessed date. In the list of references at the end of the paper, full and complete references should be given with punctuation arranged alphabetically by first author's surname.

Paper in a Journal

Brown, C. L. 2004. Content Based ESL Curriculum and Academic Language Proficiency. The Internet TESL Journal, 10(2):12 23. Retrieved on September 2012, from http://iteslj.org/Techniques/Brown CBEC.html.

Book

Seidman, Irving. (2006). Interviewing as Qualitative Research: A Guide for Researchers in Education and the Social Sciences. New York: Teachers College Press. 
Leung, C. (2012). Outcomes Based Language Teaching. In Burns A, Richards, JC (Eds.). The Cambridge Guide to Pedagogy and Practice in Language Teaching. New York: Cambridge University Press, pp. 161 179.

Electronic Sources

Burke, Jim \& Rick Smith. (2013). Academic Vocabulary List. Avaliable online at www.englishcompanion.com. Retrieved on January, 2014.

Tables and Figures

All tables and figures must be relevant and necessary; the same data should not be presented in tables and figures, and do not use short tables for information that can be easily presented using text. Tables and figures should be numbered sequentially, for example, Figure 1, Figure 2, Figure 3 and so on.

Fees and Charges

Authors are required to pay no processing fee for the online journal. Charges are incurred only upon request for processing printed journal and delivery order. 


\title{
PAPER TEMPLATE
}

IJOLTL -Indonesian Journal of Language Teaching and Linguistics p ISSN: 2502 2326; e ISSN: 2502 8278

Http: ijoltl.pusatbahasa.or.id

\author{
Paper Title (12 Bold)
}

First Author ${ }^{1}$, Second Author ${ }^{2}$ (12)

${ }^{1}$ (Department, College/ University Name, Country Name Email) (11)

2(Department, College/ University Name, Country Name Email) (11)

\begin{abstract}
Bold)
The abstract should summarize content of the paper. The length of the abstract must be no more than 150 words. Do not make references nor display equation in the abstract. Your manuscript should be printed on A4 paper $(21.0 \mathrm{~cm} \times 29.7 \mathrm{~cm})$.
\end{abstract}

Keywords (12 bold): about five keywords in alphabetical order, separated by comma.

\section{INTRODUCTION (12 BOLD)}

The introduction of the paper should explain the nature of the problem, previous work, purpose, and the contribution of the paper. The contents of each section may be provided to understand easily about the paper. (12)

\section{HEADING S (12 BOLD)}

The headings and subheadings, starting with "1. INTRODUCTION, 2. REVIEW OF LITERATURE 3. METHODS, 4. FINDINGS, 5. DISCUSSION (OR FINDINGS AND DISCUSSION), 6. CONCLUSION and REFERENCES" appear in upper and lower case letters and should be set in bold and aligned flush left. All headings from the Introduction to Acknowledgements are numbered sequentially using 1, 2, 3, etc. Subheadings are numbered 1.1, 1.2, etc. If a subsection must be further divided, the numbers should be 1.1.1, 1.1.2, etc.

The font size for heading is 12 points bold face and subsections with 12 points and not bold. Do not underline any of the headings, or add dashes, colons, etc. (12)

\section{INDENTATIONS AND EQUATIONS (12 BOLD)}

The first paragraph under each heading or subheading should have a five indentation. A colon is inserted before an equation is presented, but there is no punctuation following the equation. All equations are numbered and referred to in the text solely by a number enclosed in a round bracket. (12)

\section{FigURES AND TABLES (12 BOLD)} drafted.

To ensure a high quality product, diagrams and lettering MUST be computer

Figure captions appear below the figure, are flush left and in lower case letters. When referring to a figure in the body of the text, the abbreviation "Fig." is used. Figures should be numbered in the order they appear in the text. 
Table captions appear centered above the table in upper and lower case letters. When referring to a table in the text, no abbreviation is used. (12)

\section{CONCLUSION (12 BOLD)}

A conclusion section must be included and should indicate clearly the advantages, limitations, and possible applications of the paper. Although a conclusion may review the main points of the paper, do not replicate the abstract as the conclusion. A conclusion might elaborate on the importance of the work or suggest applications and extensions. (12)

Acknowledgements (12 Bold)

An acknowledgement section may be presented after the conclusion, if desired.(11)

REFERENCES (12 BOLD)

This heading is not assigned a number.

A reference list MUST be included using alphabetical order. Only cited text references are included. 


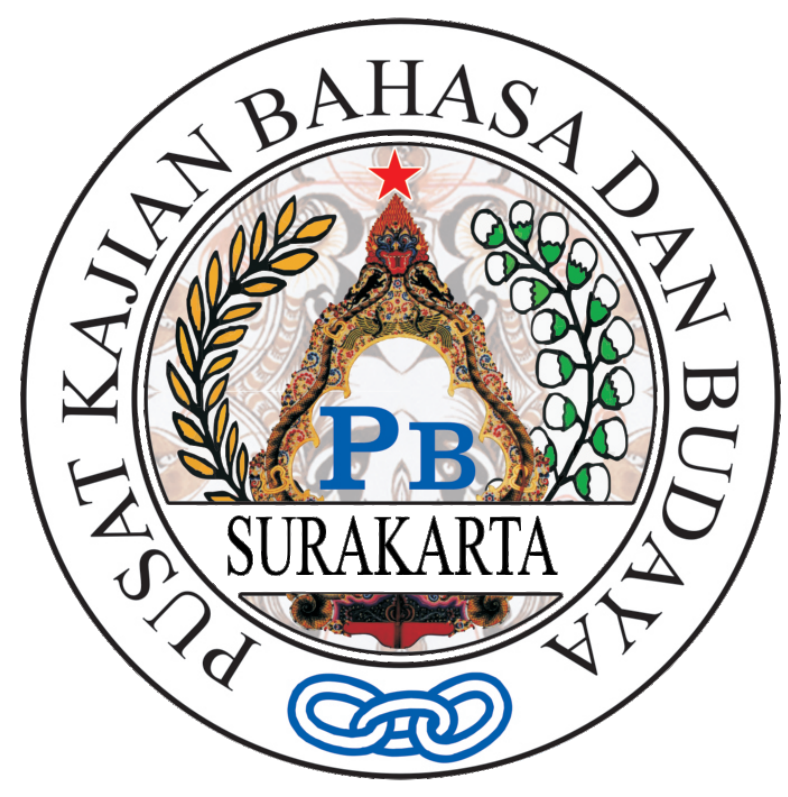

\section{IJOLTL}

Indonesian Journal of Language Teaching and Linguistics p ISSN: 2502 2326 \& e ISSN: 2502 8278

Published by:

\section{CENTER OF LANGUAGE AND CULTURE STUDIES}

Notary: Drs. Irwan Siregar, SH, M.Kn, No: 5 Dated 21 January 2015

Decree of the Ministry of Law and Human Rights of the Republic of Indonesia

No: AHU 0000276.AH.01.07 Year 2015

Dated 26 February 2015

\section{Office:}

${ }^{1}$ Samosir Street No. $23 \mathrm{Rt} 002 \mathrm{Rw} 011$ Margorejo Gilingan, Banjarsari District, Surakarta 57134, Central Java, Indonesia

${ }^{2}$ Greenville Residence Rt 002 Rw 004 Blok A11 12 Mayang, Gatak District, Sukoharjo Regency, Central Java, Indonesia Http: //ijolt1.pusatbahasa.or.id, Email: ijolt1@gmail.com

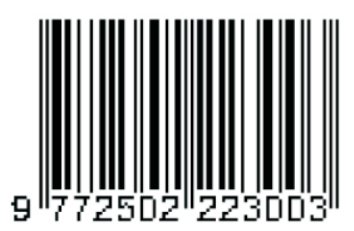

